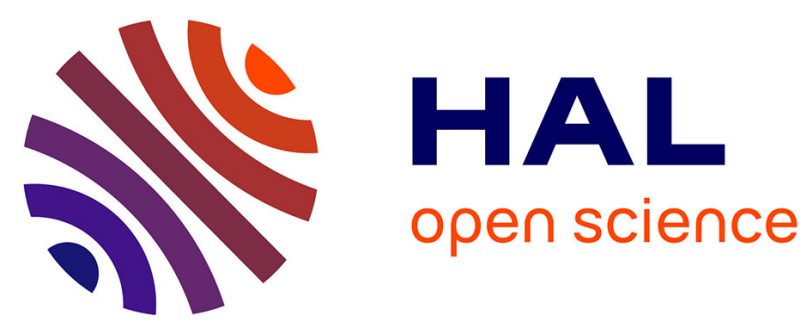

\title{
The Role of Morphology in Optically Switchable Transistors Based on a Photochromic Molecule/p-Type Polymer Semiconductor Blend
}

Marco Carroli, Duc T. Duong, Ester Buchaca-domingo, Andrea Liscio, Karl Börjesson, Martin Herder, Vincenzo Palermo, Stefan Hecht, Natalie Stingelin, Alberto Salleo, et al.

\section{To cite this version:}

Marco Carroli, Duc T. Duong, Ester Buchaca-domingo, Andrea Liscio, Karl Börjesson, et al.. The Role of Morphology in Optically Switchable Transistors Based on a Photochromic Molecule/p-Type Polymer Semiconductor Blend. Advanced Functional Materials, 2019, pp.1907507. 10.1002/adfm.201907507 . hal-02511617

\section{HAL Id: hal-02511617 \\ https://hal.science/hal-02511617}

Submitted on 18 Mar 2020

HAL is a multi-disciplinary open access archive for the deposit and dissemination of scientific research documents, whether they are published or not. The documents may come from teaching and research institutions in France or abroad, or from public or private research centers.
L'archive ouverte pluridisciplinaire HAL, est destinée au dépôt et à la diffusion de documents scientifiques de niveau recherche, publiés ou non, émanant des établissements d'enseignement et de recherche français ou étrangers, des laboratoires publics ou privés. 
DOI: $10.1002 /$ ((please add manuscript number))

Article type: Full paper

The role of morphology in optically switchable transistors based on a photochromic molecule / p-type polymer semiconductor blend

Marco Carroli, Duc T. Duong, Ester Buchaca Domingo, Andrea Liscio, Karl Börjesson, Martin Herder, Vincenzo Palermo, Stefan Hecht, Natalie Stingelin, Alberto Salleo, Emanuele Orgiu and Paolo Samori

M. Carroli, Dr. K. Börjesson, Prof. E. Orgiu, Prof. P. Samorì

Université de Strasbourg, CNRS, ISIS, 8 alleé Gaspard Monge, 67000 Strasbourg, France.

Prof. E. Orgiu

Present address: INRS-Centre Énergie Matériaux Télécommunications, 1650 Blv. LionelBoulet, J3X 1S2 Varennes, Québec.

Dr. D.T. Duong, Prof. A. Salleo

Department of Materials Science and Engineering, Stanford University, Stanford, CA 94305, USA.

E. B. Domingo, Prof. N. Stingelin

Department of Materials, Imperial College London, Exhibition Road, London, SW7 2AZ, U.K.

Dr. A. Liscio,

Istituto per la microelettronica e microsistemi - Consiglio Nazionale delle Ricerche, via del fosso del cavaliere 100, 00133 Roma, Italy.

Prof. V. Palermo

Istituto per la Sintesi Organica e la Fotoreattivita` - Consiglio Nazionale delle Ricerche, via Gobetti 101, 40129 Bologna, Italy.

Dr. M. Herder, Prof. S. Hecht

Department of Chemistry, Humboldt-Universität zu Berlin, Brook-Taylor-Str. 2, 12489

Berlin, Germany

\&

DWI - Leibniz Institute for Interactive Materials, Forckenbeckstr. 50, 52056 Aachen, Germany \& Institute of Technical and Macromolecular Chemistry, RWTH Aachen University, Worringer Weg 2, 52074 Aachen, Germany

Corresponding authors: E-mail: Samori@@unistra.fr, emanuele.orgiu@emt.inrs.ca

Keywords: photo-responsive electronics, poly(3-hexylthiophene), diarylethenes, organic field-effect transistors, photochromic molecules 


\begin{abstract}
The correlation between morphology and opto-electronic performance in organic thin-film transistors based on blends of photochromic diarylethenes (DAE) and poly(3-hexylthiophene) (P3HT) is investigated by varying molecular weight $\left(\mathrm{M}_{\mathrm{w}}=20-100 \mathrm{kDa}\right)$ and regioregularity of the conjugated polymer as well as the temperature of thermal annealing ( $\left.\mathrm{rt}-160{ }^{\circ} \mathrm{C}\right)$ in thin films. Semi-crystalline architectures of P3HT/DAE blends comprise crystalline domains, ensuring efficient charge transport, and less aggregated regions, where DAEs are located as a result of their spontaneous expulsion from the crystalline domains during the self-assembly. The best compromise between field-effect mobility $(\mu)$ and switching capabilities was observed in blends containing P3HT with $\mathrm{M}_{\mathrm{w}}=50 \mathrm{kDa}$, exhibiting $\mu$ as high as $1 \times 10^{-3} \mathrm{~cm}^{2} \mathrm{~V}^{-}$ ${ }^{1} \mathrm{~S}^{-1}$ combined with a $>50 \%$ photoswitching ratio. Higher or lower $\mathrm{M}_{\mathrm{w}}$ than $50 \mathrm{kDa}$ were found to be detrimental for field-effect mobility and to lead to reduced device current switchability. The microstructure of the regioregular P3HT blend was found to be sensitive to the thermal annealing temperature, with an increase in $\mu$ and a decrease in current modulation being observed as a response to the light-stimulus likely due to an increased P3HT-DAE segregation, partially hindering the DAE photoisomerization. Our findings demonstrate the paramount importance of fine tuning the structure and morphology of bicomponent films for leveraging the multifunctional nature of opto-electronic devices.
\end{abstract}




\section{Introduction}

The development of multiresponsive and multifunctional materials and devices represents one of the greatest challenges in organic optoelectronics. ${ }^{[1-4]}$ In this context, the functionality of solution-processed organic field-effect transistors (OFET) has been enhanced during the past years with the development of new hybrid systems incorporating functional molecules in semiconducting matrices. ${ }^{[5-9]}$ Photochromic molecules seem ideal candidates as functional components for the next generation of such multifunctional opto-electronic devices as they can be remotely controlled with high spatiotemporal resolution without generating waste products. ${ }^{[10-15]}$ Upon blending poly(3-hexylthiophene) (P3HT) and diarylethenes (DAEs), organic thin-film transistors (OTFTs) have been fabricated that displayed outstanding photoswitchable capability with the two states being extremely stable over the timescale of several months. ${ }^{[16]}$ This outstanding performance has recently led to the realization of non-volatile 8bit memory devices featuring over 256 distinct levels. ${ }^{[17]}$ Since the device performance is related to the capability of the charge carriers to relax on the DAE traps, device efficiencies can further be increased only through an optimization of the blend microstructure, as suggested by the case of organic bi-component solar cells. ${ }^{[18-19]}$ A dispersion of DAE molecules in the less aggregated portions of the polymer leads to an energetically favored interaction of the mobile charges with the hole accepting sites thereby improving the efficiency of the device response to the light stimulus. ${ }^{[20]}$

Three well-distinct parameters have been systematically adjusted in order to tune the polymer microstructure in P3HT films: the polymer molecular weight, its regioregularity and thermal annealing of thin blend films. The molecular weight was found to play crucial role in the relationship between structure and device performance. Field-effect transistor (FET) measurements on a series of low $M_{\mathrm{w}}(20-50 \mathrm{kDa})$ P3HT films showed that the hole mobility increases with the $M_{\mathrm{w}}{ }^{[21-22]}$ while films obtained from higher $M_{\mathrm{w}}$ displayed reduced crystallinity. ${ }^{[23]}$ This is explained by the improved interchain transport along the backbone of the polymer connecting the crystalline regions. ${ }^{[24]}$ However, further increases in the molecular weight $M_{\mathrm{w}}(60-331 \mathrm{kDa})$ results in a slight decrease in mobility. ${ }^{[25]}$ This is due to the detrimental role played by the enhanced average chain length that leads to a high entanglement density thereby resulting into a large fraction of amorphous regions. Previous works have shown that the regioregularity of $\mathrm{P} 3 \mathrm{HT}$ also strongly influences the packing of the polymer chains in neat and blend P3HT films. ${ }^{[26-27]}$ Indeed, regiorandom (RRa) P3HT exhibits reduced charge transport, while highly regioregular (RR) P3HT displays more efficient transport. Finally, the annealing temperature is another important parameter influencing the 
microstructure of P3HT affecting the polymer's arrangement over several length scales. ${ }^{[28]}$ The characteristic semi-crystalline morphology consisting of lamellar crystals and amorphous regions can indeed be modified via thermal annealing. Investigating the temperature dependence of the P3HT morphology can thus lead to a fine-tuning of the device properties. $^{[29-32]}$

Such knowledge on how structural modifications and/or post deposition procedures affect the final structure is instrumental when P3HT/DAE blends are considered as a mean to modulate and optimize both the hybrid film's charge transport and the capacity to respond to the lightstimulus. In such blends, the presence of molecularly disordered domains results in reduced interchain and intrachain transport as well as higher trap densities, limiting interlamellar transport and carrier mobility. Recently, we have shown that the presence of DAEs dispersed in a P3HT did not affect significantly the typical crystalline feature of the host polymer since upon spontaneous self-assembly the DAEs are expelled into the amorphous fraction of the semi-crystalline P3HT film. ${ }^{[16]}$ However, a deeper understanding of the role played by polymer molecular weight, regioregularity, and annealing temperature on the blend morphology is crucial to improve DAE dispersion throughout the film and, consequently, the device's optical response.

Here we present a study on the structural, morphological, optical, and electrical properties of blends of DAE-Me with P3HT of different weight-average molecular weight (with $M_{\mathrm{w}}$ ranging between 20 and $100 \mathrm{kDa}$ ) and varying regioregularity upon changing thermal annealing (between $\mathrm{rt}$ up to $160^{\circ} \mathrm{C}$ ), with a particular focus on the performance of the lightresponse of the bi-component devices.

\section{Results and Discussion}

Figure 1 displays the chemical structure of P3HT and DAE-Me, along with their energy level diagrams. Based on the HOMO levels required with respect to the HOMO of P3HT, DAEMe_o molecules have been designed, synthesized ${ }^{[16]}$ and used as the starting compound in order to allow electronic interaction of DAE-Me_c with polaronic charges moving in the P3HT polymer matrix. The HOMO level of DAE-Me_c lies within the bandgap of the semiconductor, thus it provides a driving force for accepting holes being transported within the polymer matrix. Such mechanism is nullified upon photoisomerization to DAE-Me_o whose HOMO level energy sits off P3HT's band gap. As a result, the optical response of the thin-film transistor is strongly affected by the ability of the photochromic molecules to undergo isomerization. The latter characteristic is determined both by the intrinsic photo- 
responsive nature of the DAE-Me and by its electronic and structural/steric interaction with the P3HT matrix. Thus, the fine tuning of the reversible light-response in the current passing through the polymer/DAE-Me hybrid film requires achieving a subtle control over film morphology.

\subsection{Role of molecular weight and regioregularity}

In neat RR P3HT, $M_{\mathrm{w}}$ strongly influences the morphology of thin films which, in turn, also affects field-effect mobility. ${ }^{[33-35]}$ Low molecular weight P3HT, with $M_{\mathrm{w}}$ below the critical molecular weight for entanglements $\left(M_{\mathrm{wc}}\right)$ of $\sim 35 \mathrm{kDa},{ }^{[16,33]}$ forms predominantly isolated crystals comprising conformationally extended chains that adopt a paraffinic-like structure. ${ }^{[36-}$ ${ }^{37]}$ In contrast, for high molecular weight P3HT $\left(M_{\mathrm{w}}>M_{\mathrm{wc}}\right)$, the average chain length largely exceeds the average molecular weight between entanglements leading to chain folding ${ }^{[38]}$ and a heterogenous microstructure comprising coexisting ordered and amorphous regions. ${ }^{[23]}$ Upon self-assembly DAE-Me molecules are prone to reside in the less aggregated portions of the polymer matrix ${ }^{[16]}$ and efficient charge transport occurs preferably in ordered regions effectively bridged by tie-chains threading through the amorphous regions. ${ }^{[24]}$ Hence, a semicrystalline structure appears being the optimal solution for high-mobility and efficient lightresponse in DAE-Me/P3HT based transistors. Three low-medium-high molecular weight P3HT $\left(\mathrm{M}_{\mathrm{w}} \approx 20,50\right.$, and $\left.100 \mathrm{kDa}\right)$ were selected as model semiconducting polymers to simultaneously optimize electrical performance and switching capabilities of the blend film. Based on previous findings, we have focused our attention to DAE-Me/P3HT with $20 \mathrm{wt} \%$ DAE-Me content as optimal ratio for the fabrication of light-responsive transistors.

Atomic force microscopy (AFM) images of RR P3HT/DAE-Me blends produced by using P3HT with different $M_{\mathrm{w}}$ are displayed in Figure 2 a-c. These films exhibit similar granular surface topography characterized by crystallites of different size, morphology and orientation, which are significantly affected by the evaporation of the solvent. ${ }^{[39]}$ Considering the high volatility of $\mathrm{CHCl}_{3}$, the lack of crystalline features in high- $\mathrm{M}_{\mathrm{w}}$ films of RR-P3HT can be expected. ${ }^{[40-41]}$ A careful quantitative analysis of these films reveals that the root mean square roughness $\left(\mathrm{R}_{\mathrm{rms}}\right)$, as determined in areas of $5.12 \times 5.12 \mu \mathrm{m}^{2}$, varies with $M_{\mathrm{w}}$. In particular, $\mathrm{R}_{\mathrm{rms}}$ $=0.50 \pm 0.01 \mathrm{~nm}$ was measured on films containing P3HT with $M_{\mathrm{w}}=20$ and $50 \mathrm{kDa}$ whereas $\mathrm{R}_{\mathrm{rms}}$ increased to $0.69 \pm 0.09 \mathrm{~nm}$ for films containing P3HT with $M_{\mathrm{w}}=100 \mathrm{kDa}$. The latter finding is in agreement with Ballantyne et al. ${ }^{[42]}$, who showed that blends containing high- $M_{\mathrm{w}}$ P3HT $\left(M_{\mathrm{w}}=121 \mathrm{kDa}\right)$ with a small molecule acceptor exhibit rougher surface compared to blends based on low- $M_{\mathrm{w}}(13 \mathrm{kDa})$. We tentatively conclude that the increased roughness 
observed in the AFM images in Figure 2c results from the self-segregation of DAE-Me aggregates unable to sit in-between the polymer chains. This interpretation is supported by the fact that AFM images of neat P3HT obtained by employing similar film processing conditions did not show the bright features which are ascribed to the DAE aggregates. ${ }^{[21,43-44]}$

Conversely, films made from solutions containing RRa P3HT with $M_{\mathrm{w}}=50 \mathrm{kDa}$ (Figure 2d) display a markedly different morphology: Despite exhibiting a texture with clusters on the hundreds of nanometer range, the absolute value of the $\mathrm{R}_{\mathrm{rms}}=0.58 \pm 0.10 \mathrm{~nm}$ is comparable to that of RR films.

The electrical characteristics of the P3HT/DAE-Me blends, when subjected to UV and visible light illumination are displayed in Figure 3. When RR P3HT is employed, upon increasing $M_{\mathrm{w}}$ from $20 \mathrm{kDa}$ to $50 \mathrm{kDa}$ we observed an improvement in field-effect mobility and light response of the devices, the latter in particular in terms of cyclability. Yet, the performance decreases when $100 \mathrm{kDa}$ RR-P3HT/DAE-Me_o is used, which we attribute to hindered charge transport due to a reduced overlap of conjugated segments. ${ }^{[42]}$ Indeed, a decrease in field-effect mobility is measured for blends containing high molecular weight P3HT (vide infra). Moreover, such devices exhibit a fatigue in the optical response over cycles which can be a consequence of further DAE-Me_o segregation (Figure 3e), in agreement with our AFM data. Conversely, in films with a large fraction of amorphous regions, DAEs seem to be relatively homogeneously dispersed within the polymer matrix $;^{[16]}$ thus it is more probable for charges to migrate and interact with hole accepting sites upon irradiation with UV light (DAE-Me_c) when DAE-Me_o molecules are well-dispersed inside the polymer matrix. As a result, under such scenario, while the field-effect mobility is lowered, the light-controlled switching ratio of conductivity improves. This behavior is quite clear in devices based on regiorandom P3HT whose films are to a greatest extent amorphous in nature. Upon comparing Figure $3 \mathrm{~b}$ with $3 \mathrm{~d}$, one can observe that field-effect mobility is three orders of magnitude lowered when RRa P3HT is employed, while the switching ratio is $100 \%$ higher as portrayed in Figure 3f. This observation provides a striking evidence that the presence of amorphous regions in the blend favors a more homogenous distribution of DAE-Me in the polymer matrix which can act as accepting sites for holes.

Figure 3e-f compares the static photo-switching (see Section 2 in the SI) characteristics of devices prepared with P3HT of different molecular weight and regioregularity. When $M_{\mathrm{w}}=$ 20 or $50 \mathrm{kDa}$ is used, little fatigue is observed. Conversely, for 100-kDa P3HT/DAE-Me_o based blends a more noticeable fatigue arises upon cycling. Such result corroborates the AFM images in Fig. 2c indicating DAE_Me_o phase segregation and aggregation in the blends 
containing RR P3HT with $\mathrm{M}_{\mathrm{w}}=100 \mathrm{kDa}$. Although all the samples exhibit switching capability, 50-kDa samples are the best compromise among the RR-P3HT blends when it comes to device performances. RR P3HT $\left(\mathrm{M}_{\mathrm{w}}=50 \mathrm{kDa}\right) / \mathrm{DAE}-\mathrm{Me}$ o o blend-based devices feature the best field-effect mobility, around $1 \times 10^{-3} \mathrm{~cm}^{2} \mathrm{~V}^{-1} \mathrm{~s}^{-1}$, as well as a photo-induced current change corresponding to $50 \%$ of the initial current with a full reversibility over several cycles. Figure 4 show that devices made of blends comprising lower (20 kDa) and higher (100 $\mathrm{kDa}$ ) molecular weight $\mathrm{P} 3 \mathrm{HT}$ exhibit comparable switching ratios, i.e. $\mathrm{SR}=\mid \mathrm{I}_{\mathrm{UV}}$,min $-\mathrm{I}_{\text {dark }} \mid / \mathrm{I}_{\text {dark }}$. However, 100-kDa RR P3HT/DAE-Me_o based devices would exhibit the lowest field-effect mobilities among the three regioregular derivatives. Blends with regiorandom P3HT represent the opposite extreme, having very low field-effect mobility $\left(\mu=2 \times 10^{-6} \mathrm{~cm}^{2} \mathrm{~V}^{-1} \mathrm{~s}^{-1}\right)$ when compared to the regioregular P3HT-based films, but with a markedly higher switching ratio (approaching 100\%). These results indicate that interconnected crystalline domains are beneficial for the field-effect mobility of the blends, at the cost of lower charge trapping efficiency of DAE-Me_c. When the films contain a higher fraction of amorphous regions such as in RRa P3HT/DAE-Me_o films, the SR is higher as a result of a lower chain-to-chain aggregation capacity with respect to the RR case, leading to a better dispersion of the photochromic molecules. Concerning the electrical performances, one could conclude that a nearly negligible dependence on polymer molecular weight was observed.

\subsection{Annealing temperature}

Having identified the best compromise in terms of high field-effect mobility, high switching ratio and fatigue-free cyclability, we further focused on $50 \mathrm{kDa}$ RR P3HT/DAE-Me_o-based blends.

It is well known that thermal annealing typically increases the degree of crystallinity in semicrystalline polymers by 'healing' structural defects within the crystalline regions and enlarging the lateral size of the latter as well as, in some cases, the lamellar crystal thickness. Such structural changes are usually beneficial for charge transport. However, one of the biggest challenges that remains in P3HT/DAE-Me_o structure control is understanding the relationship between the photo-switching capability of conductivity and degree of crystallinity. Since standard operating temperature for most commercial devices ranges from $0{ }^{\circ} \mathrm{C}$ to $85^{\circ} \mathrm{C}$, elucidating the device and material behavior as a function of temperature is rather important in view of future technological applications.

As previously discussed, DAEs segregation from the polymer matrix can result in a substantial decrease of the photo-current modulation due to reduced interaction with mobile 
charges, which are transported through the conjugated polymer backbone. In case of DAEs aggregation, pronounced fatigue in cyclability could also occur due to mechanical constrains imposed on the DAE-Me ring opening by the surrounding polymer matrix. An insight into the microstructure of P3HT/DAE-Me_o blend films upon annealing can be obtained by correlating the morphological, thermal and structural data obtained on films with the electrical properties of the device.

Figure $4 \mathrm{~b}$ portrays the dependence of the field-effect mobility with annealing temperature for blends containing $50 \mathrm{kDa}$ RR P3HT. For as-spun P3HT/DAE-Me_o films a FET mobility of $1.0 \times 10^{-3} \mathrm{~cm}^{2} \mathrm{~V}^{-1} \mathrm{~s}^{-1}$ is measured and a switching transfer characteristic featuring $50 \% \mathrm{SR}$ which can be fully controlled by light irradiation. Similar electrical performances are observed for annealing temperatures up to $80^{\circ} \mathrm{C}$. Our experiments reveal that for films annealed at $\mathrm{T}>80^{\circ} \mathrm{C}$ a notable effect on the current-voltage characteristics and their modulation under UV or visible light irradiation $(\lambda=313 \mathrm{~nm}$ with power density $=0.1$ $\mathrm{mW} \cdot \mathrm{cm}^{-2}$ whereas at $\lambda=546 \mathrm{~nm}$ the power density $=1 \mathrm{~mW} \cdot \mathrm{cm}^{-2}$ ) is observed. Finally, the films annealed at $\mathrm{T}>140{ }^{\circ} \mathrm{C}$ yielded devices with field-effect mobility of $1.0 \times 10^{-2} \mathrm{~cm}^{2} \mathrm{~V}^{-1} \mathrm{~s}^{-1}$, although accompanied with remarkably lower SR (see Figure S1). In essence, while the electrical conductivity of the devices is enhanced by annealing, the switching capability was found to degrade.

AFM investigation clearly shows that the presence of DAEs strongly affects the properties of the pristine P3HT film. While the $\mathrm{R}_{\mathrm{rms}}$ value of pristine P3HT film depends on the annealing temperature, no remarkable variation is achieved in the blend up to $135^{\circ} \mathrm{C}$ (Fig. S5a,c). Similar behavior is observed for the films' mechanical properties, as performed by AFM phase imaging (Fig. S5b,d).

Since GIWAXS did not reveal any or negligible crystallinity increase/variation upon annealing (Fig. S3), such behavior may be ascribed to the possible change in size of the polymer aggregated regions with increasing temperature.

In order to investigate the order and the percentage of the aggregated portions of P3HT in blends upon annealing, we employed linear absorption spectroscopy. The absorption spectrum of RR P3HT thin films can be comprehensively explained using a weakly interacting $\mathrm{H}$-aggregate model. ${ }^{[45-46]}$ A decrease in excitonic bandwidth, $W$, (Figure 5a) can be generally associated with a reduced interchain coupling as a result of a more pronounced 1-D character of the exciton localization. As this latter phenomenon is indicative of a higher degree of torsional order, our comparative experiments revealed: (i) a general increase of the degree of torsional order upon annealing both in P3HT and P3HT/DAE-Me_o films; (ii) a 
higher degree of order in P3HT/DAE-Me_o films as opposed to those made from neat polymer. Regarding the percentage of aggregates (Figure 5b), a general tendency to increase with temperature could be observed for both neat and blended films, with a percentage of aggregates that is comparable within experimental error. We attribute such a possible increase in the lamellar thickness that could be induced by a lower torsional back-bone disorder in blend vs. neat P3HT films, to the fact that DAE lowers the melting point of the P3HT (Figure S2) and annealing is performed in a semi-liquid state above the melting of the DAE component; hence, at the same annealing temperature, the P3HT molecules will diffuse more easily than in the neat material, leading to better order (as already alluded to above).

In thin films, the ring-opening quantum yield seems to be independent of the annealing temperature (0.31-0.33\%) and molecular weight $(0.34 \%, 0.31 \%$, and $0.31 \%$ for blends with $20 \mathrm{kDa}, 35 \mathrm{kDa}$, and $100 \mathrm{kDa}$ P3HT, respectively). However, as revealed by Figure S7, the starting absorbances are quite similar from room temperature up to annealing temperatures of $80{ }^{\circ} \mathrm{C}$. Yet, upon annealing at $95^{\circ} \mathrm{C}$, the initial absorbance would decrease to less than half of the initial value while at higher annealing temperatures no isomerization event could be seen at all. Hence, we put forward the hypothesis that at high annealing temperatures $\left(\mathrm{T} \geq 95^{\circ} \mathrm{C}\right)$, DAE either starts to decompose or goes into an aggregation state that is unable to undergo photoisomerisation. Analogously, no open-to-closed isomerisation could be measured through the electrical response to light stimuli. Current change upon irradiation were found to be quenched as shown in Figure 4b. Such an effect cannot be related to the DAE molecules degradation: TG analysis showed indeed that DAE-Me_o is stable up to $253{ }^{\circ} \mathrm{C}$, then it decomposes in an exothermic process. However, a phase transition at $91{ }^{\circ} \mathrm{C}$ could be observed in the DTA traces (Figure S9), indicating that DAE-Me_o melts at this temperature. Such finding corroborates the decrease in quantum yield and electrical switching observed on films annealed at $90{ }^{\circ} \mathrm{C}$ or at higher temperature. As to the switching speed of the device, our work indicates that no change in QY would occur upon varying $\mathrm{Mw}$ or upon annealing. Hence, device switching speed will be dominated solely by charge carrier mobility, which did not change significantly with $\mathrm{Mw}$ or increased mildly upon annealing. The device switching speed is therefore not expected to change significantly with respect to our earlier report. ${ }^{[16]}$

\section{Conclusion}

Photochromic DAE derivatives were dispersed in a polymeric semiconducting matrix in order to confer a light responsive nature to thin-film transistors. In order to maximize both, the capacity of DAE-Me to trap the holes transported within the P3HT matrix when in the closed 
isomer and to de-trap them when toggled back to the open isomer, the absence of phase separation at the mesoscale between the two components is required. Therefore, understanding and controlling the structure and morphology dependent properties in P3HT/DAE-Me_o blends is key to tune the devices' multifunctionality. Upon varying molecular weight and regioregularity of the P3HT in the blend, it was possible to conclude that DAE-Me_o phase segregation within a P3HT matrix is strongly correlated to the optoelectronic properties of the bi-functional FET. The films made with P3HT possessing higher regioregularity exhibit enhanced electrical performance yet accompanied by a more modest photo-response.

Reduced photoresponse is measured for annealing temperatures higher than $80^{\circ} \mathrm{C}$. The Spano model together with UV-vis absorption measurements and quantum yield observations suggests that the switching performance is lowered possibly because the presence of DAEMe_o lowers the P3HT melting temperature, assisting in increasing the lamellar crystal thickness without necessarily affecting the overall degree of crystallinity during thermal annealing. Finally, at higher temperature than $140{ }^{\circ} \mathrm{C}$, the photoresponse of the transfer curves is lost due to the melting of DAE-Me_o. This study offers an important insight on bifunctional devices exploiting P3HT/DAE-Me_o. The regioregularity and annealing temperature during process fabrication have to be chosen/controlled in order to tune the resulting device properties. Moreover, future technology based on such blend must consider the temperature window where devices can operate while retaining the initial characteristics.

\section{Experimental Section}

Device preparation and electrical measurements: All devices were prepared on $\mathrm{Si} \mathrm{n}^{++} / \mathrm{SiO}_{2}$ substrates with pre-patterned Au bottom electrodes, with a P3HT/DAE-Me_o weight ratio of 4:1 and $70 \mathrm{~nm}$ active layer thickness (spin-coated from chloroform). Annealing lasts $1 \mathrm{~h}$ on a hot plate in inert atmosphere at a given temperature. The value of the gate voltage $\mathrm{V}_{\mathrm{G}}$ for electrical transfer characteristics is fixed at $-60 \mathrm{~V}$. To compare switching capabilities of several devices, the drain current $I_{D}$ is normalized by the $I_{0}$, which is the value of the drain current measured in the initial step.

Films of different thicknesses for absorption experiments are fabricated on glass substrates. Spectra are obtained using a Varian Cary 6000i UV-Vis-NIR spectrophotometer and fitted to a modified Spano model to yield the percent aggregate and the excitonic bandwidth W. 
Differential scanning calorimetry (DSC) measurements were conducted under nitrogen at scan rate of $20{ }^{\circ} \mathrm{C} \mathrm{min}-1$ for heating and $10{ }^{\circ} \mathrm{C} \mathrm{min}-1$ for cooling with a Mettler Toledo DSC822 instrument. Neat material and blend powders were produced by preparing homogeneous solutions of $0.5 \mathrm{wt} \%$ total material content in chloroform, followed by casting onto glass slides. The solvent was evaporated at ambient pressure in air. 2-4 mg material from such films was used for the DSC experiments. Complete melting of primary crystals as well as melting of the neat materials correspond to the end melting temperatures in the DSC thermograms.

\section{Photochemical quantum yield in thin films of P3HT/DAE-Me_o(20\%)}

The photo-isomerization quantum yields of the closed to open isomerization of DAEMe were determined by monitoring the absorbance change (at $535 \mathrm{~nm}$; using a JASCO V630 spectrophotometer) of DAE-Me_c with respect to irradiation time (irradiation wavelength 535 $\mathrm{nm}$; using a SPEX fluorolog, Horiba). ${ }^{[47]}$ In solution the change in absorbance with respect to time is a function of the photon flux $(\omega)$, quantum yield $(\phi)$, molar absorptivity $(\varepsilon)$, length of the optical path (1), Avogadro's number $\left(\mathrm{N}_{\mathrm{A}}\right)$, fraction of absorbed photons $\left(1-10^{-\mathrm{Abs}}\right)$, and the volume of the sample (V).

$$
\frac{d A b s}{d t}=-\frac{\varphi \cdot \omega \cdot \epsilon \cdot l \cdot\left(1-10^{-A b s}\right)}{N_{A} \cdot V}
$$

This equation, which was used to determine the photon flux, can be modified to be applicable on thin films by introducing a unit correction factor (that compensates for the non SI units in the molar absorptivity factor), replacing the volume of the sample with the irradiated area, and by modify the unit of the photonflux from Einstein $/ \mathrm{s}$ to Einstein $/\left(\mathrm{s}^{*} \mathrm{~cm}^{2}\right)$.

$$
\frac{d A b s}{d t}=-\frac{\varphi \cdot \omega \cdot \epsilon \cdot \text { unit correction factor } \cdot\left(1-10^{-A b s}\right)}{N_{A} \cdot \text { area }}
$$

The photon flux (at $535 \mathrm{~nm}$ ) was determined using the chemical standard Aberchrome 670, using exactly the same geometry (including a mask with known area) as used when measuring on the films. ${ }^{[48]}$ The molar absorptivity of DAE-Me in blended films was approximated with the solution value $\left(19000 \mathrm{M}^{-1} \mathrm{~cm}^{-1}\right)$. An in-house MATLABC script was used to fit the absorbance contribution of DAE-Me to theory in which the differential equations where solved in each fitting step.

Atomic Force Microscopy (AFM) 
Topographic and phase-imaging measurements were obtained in air by employing a commercial microscope Multimode 8 (Bruker). In order to obtain a sufficiently large and detectable mechanical deflection, we used $\left(\mathrm{k}=40 \mathrm{Nm}^{-1}\right)$ silicon tips (NCHV-A, Bruker) with oscillating frequencies in the range between $270-400 \mathrm{KHz}$. The mean square roughness $\left(\mathrm{R}_{\mathrm{rms}}\right)$ has been estimated by averaging the values obtained on several $5.12 \times 5.12 \mu \mathrm{m}^{2}$ images $(1024 \times 1024$ pixels) acquired on different regions of the sample (corresponding to about 100 $\mu \mathrm{m}^{2}$ of sampled surface). Raw AFM data were treated by using histogram flattening procedures to remove the experimental artefacts due to the piezo-scanners. In the phaseimaging mode, the measured phase-shift is the difference between the output and the input signals, mapping differences in mechanical properties of the surface: such as stiffness, rigidity, friction, adhesion.

\section{Acknowledgements}

We acknowledge funding from the European Commission through the Marie SklodowskaCurie ITN project iSwitch (GA-642196), the Marie Sklodowska-Curie ITN project SYNCHRONICS (GA-643238), the ERC projects SUPRAFUNCTION (GA-257305) and LIGHT4FUNCTION (GA-308117), the Agence Nationale de la Recherche through the Labex project CSC (ANR-10-LABX-0026 CSC) within the Investissement d'Avenir program (ANR-10-120 IDEX-0002-02), and the International Center for Frontier Research in Chemistry (icFRC) as well as the German Research Foundation (via SFB 765 and SFB 951).

Received: ((will be filled in by the editorial staff))

Revised: ((will be filled in by the editorial staff)) Published online: ((will be filled in by the editorial staff))

\section{References}

[1] B. C. Thompson, Y. G. Kim, T. D. McCarley, J. R. Reynolds, J Am Chem Soc 2006, 128, 12714.

[2] B. Lebeau, P. Innocenzi, Chem Soc Rev 2011, 40, 886.

[3] I. Ratera, J. Veciana, Chem Soc Rev 2012, 41, 303.

[4] M. Muccini, Nat Mater 2006, 5, 605.

[5] W. P. Wu, Y. Q. Liu, D. B. Zhu, Chem Soc Rev 2010, 39, 1489.

[6] Z. Y. Chen, M. J. Lee, R. S. Ashraf, Y. Gu, S. Albert-Seifried, M. M. Nielsen, B. Schroeder, T. D. Anthopoulos, M. Heeney, I. McCulloch, H. Sirringhaus, Adv Mater 2012, 24, 647.

[7] Y. L. Guo, G. Yu, Y. Q. Liu, Adv Mater 2010, 22, 4427.

[8] M. Mas-Torrent, C. Rovira, Chem Soc Rev 2008, 37, 827.

[9] S. Holliday, J. E. Donaghey, I. McCulloch, Chem Mater 2014, $26,647$.

[10] R. Gostl, A. Senf, S. Hecht, Chem Soc Rev 2014, 43, 1982.

[11] L. Wang, Q. Li, Chem Soc Rev 2018, 47, 1044. 
[12] E. Orgiu, P. Samorì, Adv Mater 2014, 26, 1827.

[13] S. Kawata, Y. Kawata, Chem Rev 2000, 100, 1777.

[14] D. Dulic, S. J. van der Molen, T. Kudernac, H. T. Jonkman, J. J. D. de Jong, T. N. Bowden, J. van Esch, B. L. Feringa, B. J. van Wees, Phys Rev Lett 2003, 91, 207402.

[15] P. Andersson, N. D. Robinson, M. Berggren, Synthetic Met 2005, 150, 217.

[16] E. Orgiu, N. Crivillers, M. Herder, L. Grubert, M. Patzel, J. Frisch, E. Pavlica, D. T. Duong, G. Bratina, A. Salleo, N. Koch, S. Hecht, P. Samorì, Nat Chem 2012, 4, 675.

[17] T. Leydecker, M. Herder, E. Pavlica, G. Bratina, S. Hecht, E. Orgiu, P. Samorì, Nat Nanotechnol 2016, 11, 769.

[18] M. Campoy-Quiles, T. Ferenczi, T. Agostinelli, P. G. Etchegoin, Y. Kim, T. D. Anthopoulos, P. N. Stavrinou, D. D. C. Bradley, J. Nelson, Nat Mater 2008, 7, 158.

[19] H. Hoppe, N. S. Sariciftci, J Mater Chem 2006, 16, 45.

[20] M. El Gemayel, K. Börjesson, M. Herder, D. T. Duong, J. A. Hutchison, C. Ruzie, G. Schweicher, A. Salleo, Y. Geerts, S. Hecht, E. Orgiu, P. Samorì, Nat Commun 2015, 6, 6330 .

[21] R. J. Kline, M. D. McGehee, E. N. Kadnikova, J. S. Liu, J. M. J. Frechet, M. F. Toney, Macromolecules 2005, 38, 3312.

[22] A. Zen, J. Pflaum, S. Hirschmann, W. Zhuang, F. Jaiser, U. Asawapirom, J. P. Rabe, U. Scherf, D. Neher, Adv Funct Mater 2004, 14, 757.

[23] M. Brinkmann, P. Rannou, Adv Funct Mater 2007, 17, 101.

[24] R. Noriega, J. Rivnay, K. Vandewal, F. P. V. Koch, N. Stingelin, P. Smith, M. F. Toney, A. Salleo, Nat Mater 2013, 12, 1038.

[25] A. G. Dixon, R. Visvanathan, N. A. Clark, N. Stingelin, N. Kopidakis, S. E. Shaheen, J Polym Sci Pol Phys 2018, 56, 31.

[26] R. Mauer, M. Kastler, F. Laquai, Adv Funct Mater 2010, 20, 2085.

[27] H. Sirringhaus, P. J. Brown, R. H. Friend, M. M. Nielsen, K. Bechgaard, B. M. W. Langeveld-Voss, A. J. H. Spiering, R. A. J. Janssen, E. W. Meijer, P. Herwig, D. M. de Leeuw, Nature 1999, 401, 685.

[28] S. Hugger, R. Thomann, T. Heinzel, T. Thurn-Albrecht, Colloid Polym Sci 2004, 282, 932.

[29] Y. C. Huang, S. Y. Chuang, M. C. Wu, H. L. Chen, C. W. Chen, W. F. Su, J Appl Phys 2009, 106, 034506.

[30] M. Reyes-Reyes, K. Kim, D. L. Carroll, Appl Phys Lett 2005, 87, 083506.

[31] F. Padinger, R. S. Rittberger, N. S. Sariciftci, Adv Funct Mater 2003, 13, 85.

[32] Y. Ishiguro, R. Hayakawa, T. Chikyow, Y. Wakayama, Acs Appl Mater Inter 2014, 6, 10415.

[33] F. P. V. Koch, J. Rivnay, S. Foster, C. Muller, J. M. Downing, E. Buchaca-Domingo, P. Westacott, L. Y. Yu, M. J. Yuan, M. Baklar, Z. P. Fei, C. Luscombe, M. A. McLachlan, M. Heeney, G. Rumbles, C. Silva, A. Salleo, J. Nelson, P. Smith, N. Stingelin, Prog Polym Sci 2013, 38, 1978.

[34] K. Tremel, S. Ludwigs, Adv. Polym. Sci. 2014, 265, 39.

[35] D. Chlebosz, L. Janasz, W. Pisula, A. Kiersnowski, Polimery-W 2016, 61, 433.

[36] M. Brinkmann, J Polym Sci Pol Phys 2011, 49, 1218.

[37] T. Q. Nguyen, V. Doan, B. J. Schwartz, J Chem Phys 1999, 110, 4068.

[38] T. Odijk, Macromolecules 1983, 16, 1340.

[39] J. F. Chang, B. Q. Sun, D. W. Breiby, M. M. Nielsen, T. I. Solling, M. Giles, I. McCulloch, H. Sirringhaus, Chem Mater 2004, 16, 4772.

[40] J. Clark, J. F. Chang, F. C. Spano, R. H. Friend, C. Silva, Appl Phys Lett 2009, 94, 163306.

[41] H. H. Yang, S. W. LeFevre, C. Y. Ryu, Z. N. Bao, Appl Phys Lett 2007, 90, 172116. 
[42] A. M. Ballantyne, L. Chen, J. Dane, T. Hammant, F. M. Braun, M. Heeney, W. Duffy, I. McCulloch, D. D. C. Bradley, J. Nelson, Adv Funct Mater 2008, 18, 2373.

[43] H. L. Hu, K. Zhao, N. Fernandes, P. Boufflet, J. H. Bannock, L. Y. Yu, J. C. de Mello, N. Stingelin, M. Heeney, E. P. Giannelise, A. Amassian, J Mater Chem C 2015, 3, 7394.

[44] R. J. Kline, M. D. McGehee, E. N. Kadnikova, J. S. Liu, J. M. J. Frechet, Adv Mater 2003, 15, 1519.

[45] F. C. Spano, J Chem Phys 2005, 122, 234701.

[46] F. C. Spano, Chem Phys 2006, 325, 22.

[47] K. Stranius, K. Börjesson, Sci Rep 2017, 7, 41145.

[48] A. P. Glaze, H. G. Heller, J. Whittall, J. Chem. Soc. Perkin Trans. 2 1992, 591.

a)

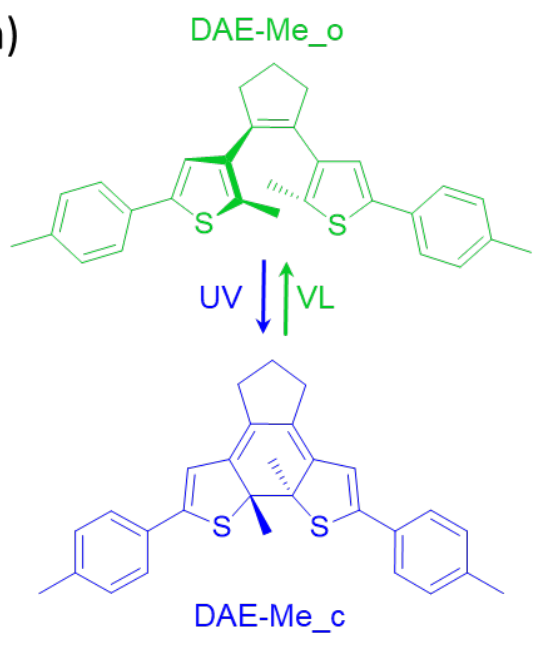

b)

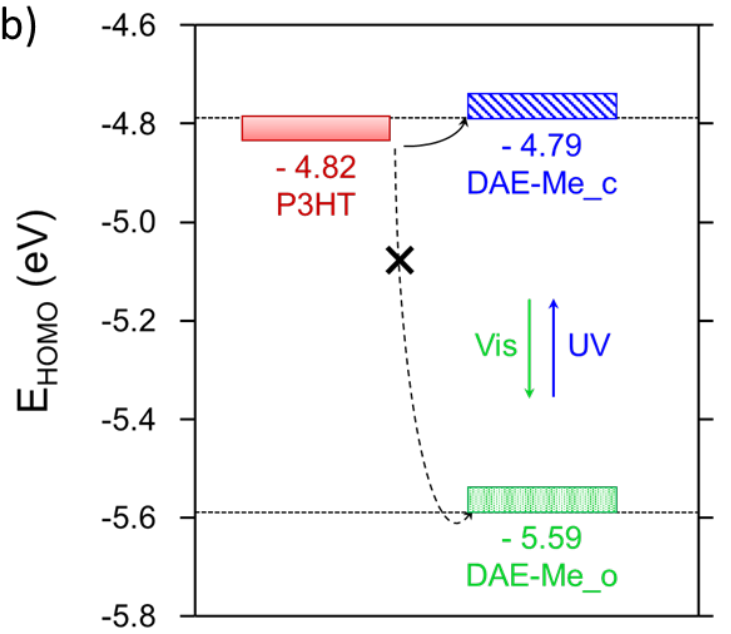

Figure 1. a) Schematic DAE-Me photo-isomerization between two thermodynamically stable forms. When irradiated with a UV light, DAE-Me molecules can undergo isomerization from an open form (DAE-Me_o) into a closed one (DAE-Me_c). The back isomerization, from DAE-Me_c to DAE-Me_o, occurs upon irradiation with visible light. b) HOMO energy levels of DAE-Me measured by cyclovoltammetry in comparison with those of P3HT. ${ }^{[20]}$ 
a) 20 kDa RR-P3HT blend

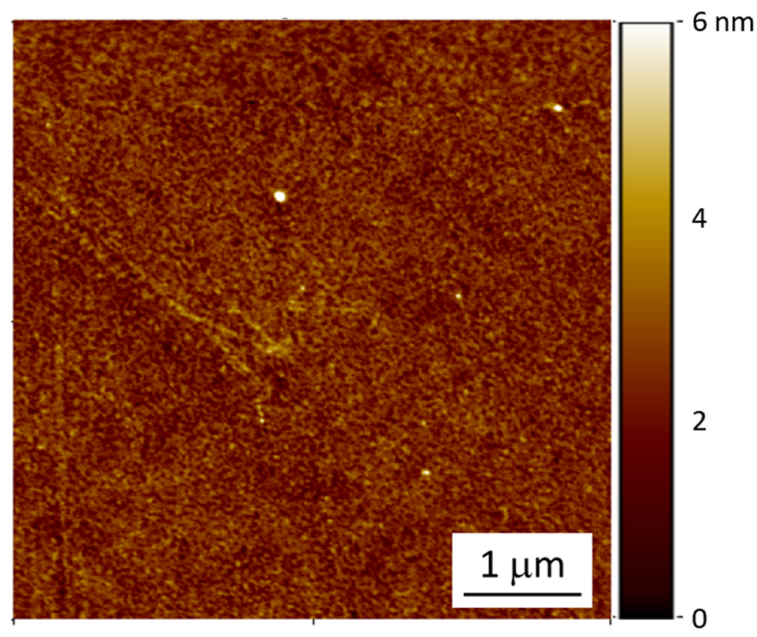

c) $100 \mathrm{kDa}$ RR-P3HT blend

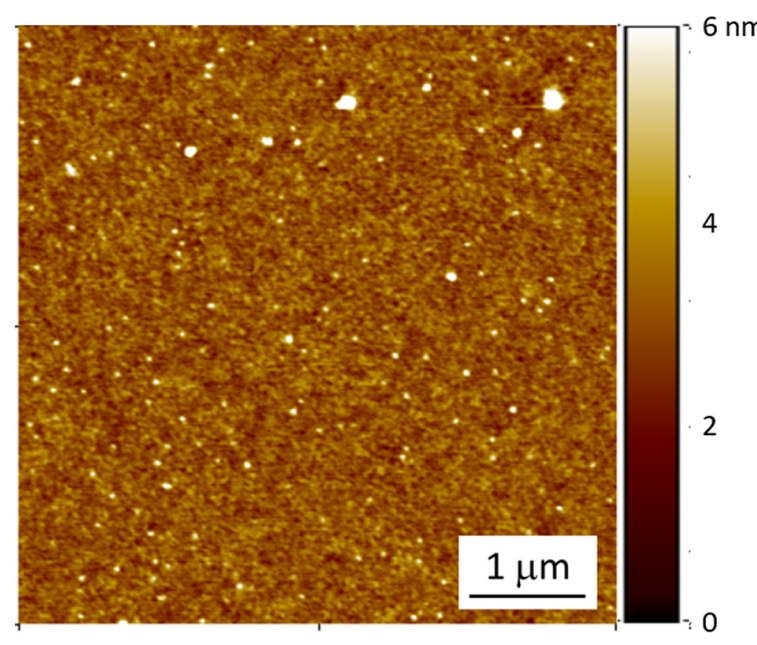

b) 50 kDa RR-P3HT blend

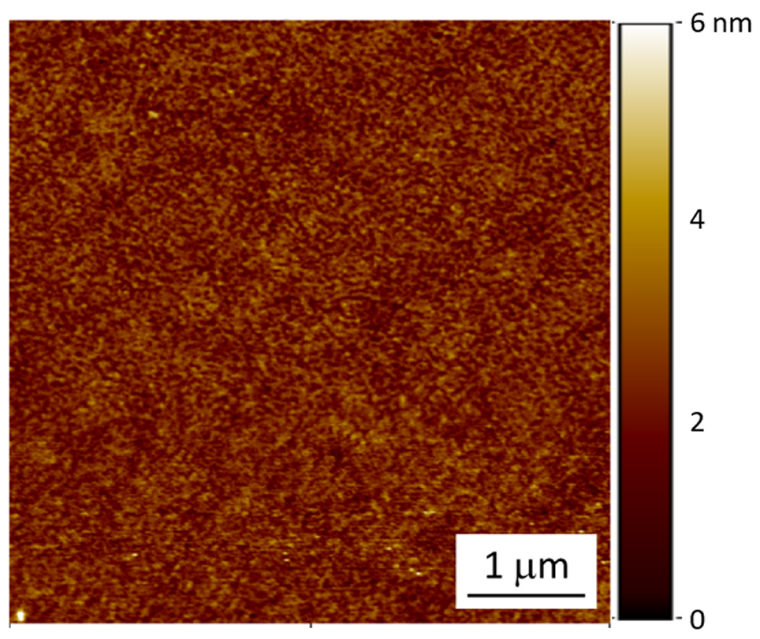

d) $50 \mathrm{kDa}$ RRa-P3HT blend

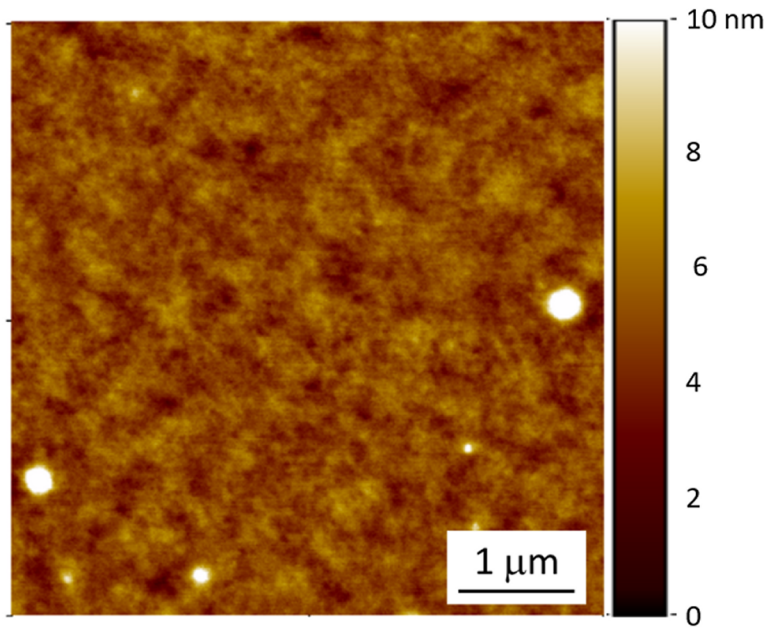

Figure 2. Height AFM images recorded in tapping mode of a $20 \mathrm{wt} \%$ DAE-Me_o blend with P3HT (a) RR and $M_{w}=20 \mathrm{kDa}$, (b) RR and $\mathrm{M}_{\mathrm{w}}=50 \mathrm{kDa}$, (c) RR and $\mathrm{M}_{\mathrm{w}}=100 \mathrm{kDa}$, and (d) RRa and $\mathrm{M}_{\mathrm{w}}=50 \mathrm{kDa}$. Z-scales: (a-c) $6 \mathrm{~nm}$, (d) $10 \mathrm{~nm}$. 

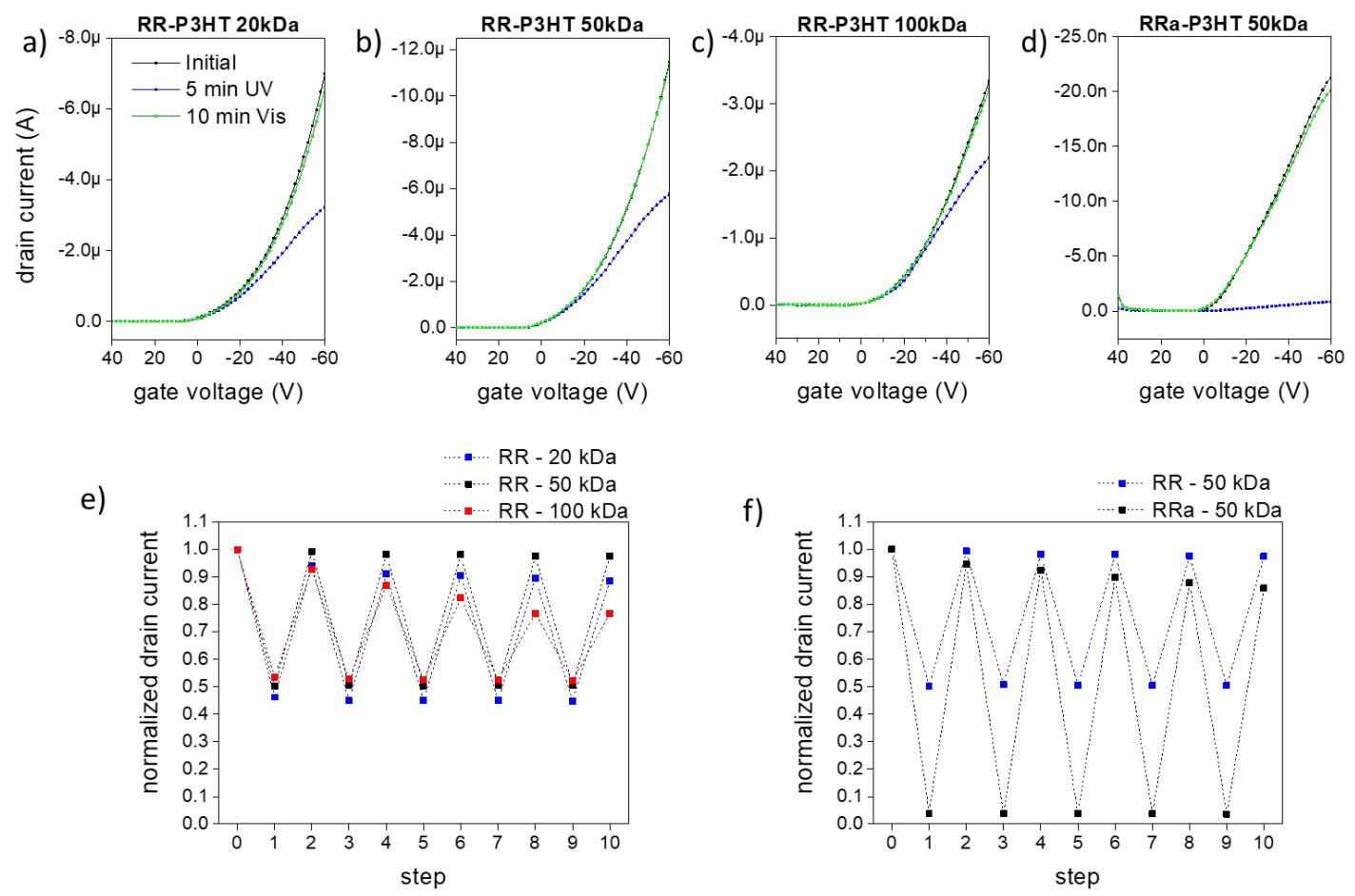

Figure 3. The photo-reversible transfer characteristics of transistor containing $20 \mathrm{wt} \% \mathrm{DAE}-$ Me_o blended with RR-P3HT with $M_{\mathrm{w}}$ of (a) 20, (b) 50, (c) $100 \mathrm{kDa}$, and (d) RRa-P3HT $M_{\mathrm{w}}$ $=50 \mathrm{kDa}\left(\mathrm{W}=10^{4} \mu \mathrm{m}, \mathrm{L}=20 \mu \mathrm{m}, \mathrm{V}_{\mathrm{DS}}=-60 \mathrm{~V}\right)$. Comparative plot of the normalized drain current upon multiple cycles of irradiation with UV and visible light for blends containing (e) RR-P3HT at different $M_{\mathrm{w}}$, and (f) regioregular vs. regiorandom P3HT at identical $M_{\mathrm{w}}=50$ $\mathrm{kDa}$.
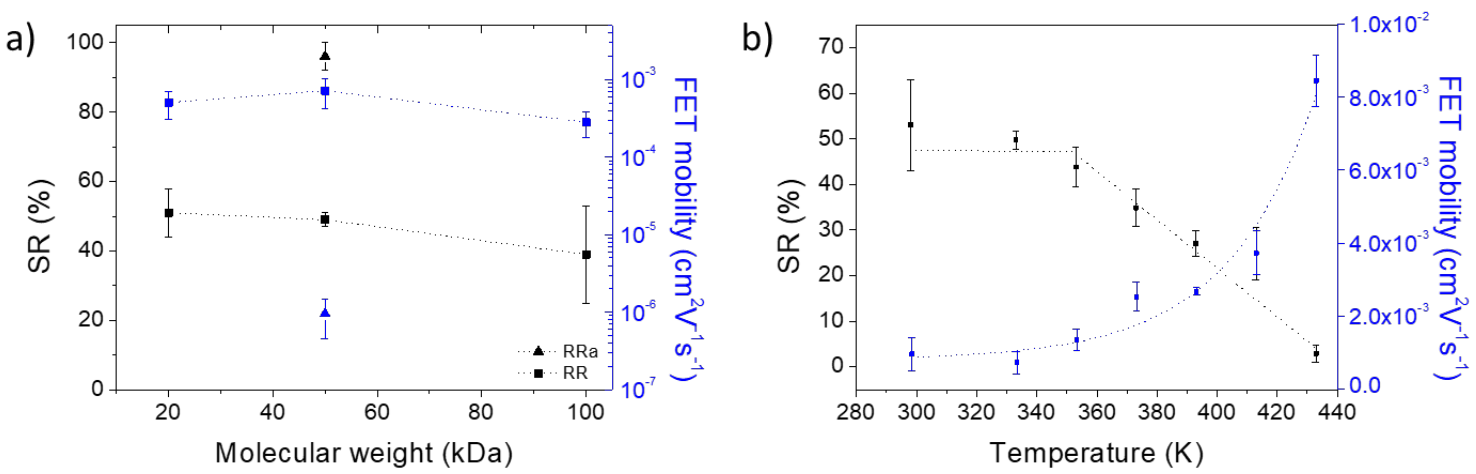

Figure 4. Switching ratio (SR) of device conductivity as a result of light irradiation and the field-effect mobility of P3HT/DAE-Me_o blend devices prepared with polymers (a) at different molecular weight, and (b) annealing temperatures (measurements done on blends based on $50 \mathrm{kDa}$ RR P3HT). 

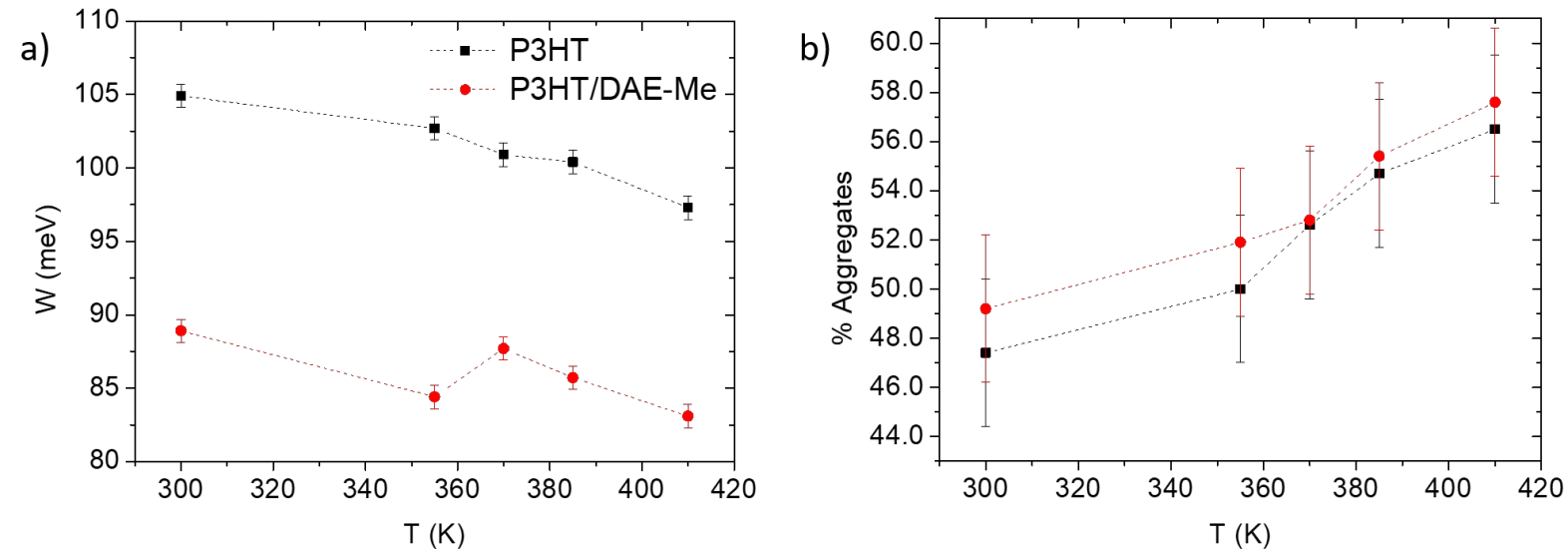

Figure 5. Exciton bandwidth (a) and percentage of aggregates (b) in pure and blended P3HT in function of annealing temperature. 